\title{
Concepções e percepções de pesquisadores sobre avaliação de materiais didáticos digitais no contexto de curadoria digital
}

\author{
Katia Alexandra de Godoi e Silva ${ }^{1}$, Maria Elizabeth Bianconcini de \\ Almeida $^{2}$ e António Pedro Costa ${ }^{3}$
}

\footnotetext{
${ }^{1}$ Mestrado em Ensino de Ciências e Matemática da Uniderp e Programa de pós-graduação em Metodologias para o Ensino de Linguagens e suas Tecnologias da Unopar, Brasil | katia.a.silva@anhanguera.com | https://orcid.org/0000-0002-6003-6852

${ }^{2}$ Vice-coordenadora do Programa pós-graduação em Educação e Currículo da Pontifícia Universidade Católica de São Paulo, Brasil | bethalmeida@pucsp.br | https://orcid.org/00000001-5793-2878

${ }^{3}$ Researcher at the University of Aveiro, Portugal | apcosta@ua.pt | https://orcid.org/00000002-4644-5879
}

Resumo: A avaliação de materiais didáticos digitais realizada por professores, vem sendo discutida por diversos autores, os quais são proponentes de instrumentos avaliativos, numa abordagem de classificação final ou numa perspectiva contextual. Tais aspectos podem levar os professores a refletirem sobre o processo dessa avaliação e, de que forma os materiais no formato digital, poderiam ser analisados no contexto da curadoria digital. Assim, o presente estudo objetiva compreender as concepções de pesquisadores sobre curadoria digital e suas percepções sobre como orientar os professores no processo de escolha de materiais didáticos digitais. Os participantes deste estudo são estudantes em um programa de pós-graduação stricto sensu, em uma universidade particular e comunitária, no estado de São Paulo, que atuam também como professores em Educação on-line e mediadores da formação de professores voltada à Curadoria Digital. Trata-se de pesquisa com abordagem qualitativa, que se apoia em dados construídos por meio de entrevistas, como processo reflexivo. A apreciação das entrevistas se dá a partir da análise de conteúdo, com o uso do software de análise qualitativa de dados o webQDA. Os resultados revelam possibilidades de diálogo entre o processo de escolha e avaliação de MDDs, o processo de CD, e o processo de ensino, o que sugere uma nova abordagem de formação de professores a partir do contexto em que estão inseridos. Uma formação voltada à $C D$, pois, na atualidade, revela-se como uma exigência e atribuição do professor, que precisa ser preparado para assumir tal responsabilidade.

Palavras-chave: Tecnologia Educacional; Seleção do Material Didático; Cultura Digital; Pesquisa Qualitativa; webQDA

\section{Researchers Conceptions and Perceptions about Digital Didactic Materials Evaluation in the Digital Curation}

\begin{abstract}
The evaluation of digital learning materials, carried out by professors, has been discussed by several authors, who are proponents of evaluative instruments, in a final classification approach or in a contextual perspective. Such aspects can lead teachers to reflect on the process of this evaluation and, in what way the materials in digital format, could be analyzed in the context of digital curation. Thus, the objective is to understand the researcher conceptions about Digital Curation (DC) and their perceptions about how to guide professors in Digital Didactic Materials (DDM) choice. The investigated researchers are students in a stricto sensu postgraduation program at a private and community university in the São Paulo state. They also work as professors in online education and professors formation mediators focused on DC. It is about a qualitative approach based on data constructed through interviews as a reflexive process. The interviews appreciation is given from the content analysis, using the data qualitative organization software, the webQDA. The results reveal dialogue possibilities among the choice process and DDM evaluation, DC process, and teaching process, suggesting a professors new formation approach from the context in which they are inserted. A formation focused on DC because it is a professor requirement and attribution that must be prepared to assume such responsibility.
\end{abstract}

Keywords: Educational Technology; Selection of Teaching Material; Digital Culture; Qualitative Research; webQDA. 


\section{Introdução}

Os impactos provocados pelas tecnologias digitais em nosso dia a dia têm sido objeto constante para novas pesquisas científicas, pois é necessário encontrar respostas para diferentes questões, como, por exemplo, as relacionadas às tecnologias empregadas na educação: "Quais são as implicações do crescimento da oferta de Materiais Didáticos Digitais (MDDs) para os processos de ensino e aprendizagem?"; "Como e por quem esses materiais, no formato digital, estão sendo selecionados?"

Nesse contexto permeado por mudanças tecnológicas digitais, percebem-se diversos desafios, dentre eles, o emprego das ferramentas colaborativas da web 2.0, que permite aos usuários da Internet produzirem, armazenarem e publicarem informações em ritmo acelerado. No entanto, os desafios digitais aplicam-se também às iniciativas governamentais, voltadas à Educação, e não apenas a pessoas. Schlünzen Jr (2009) e Gonsales (2014), explicam que anualmente, uma quantidade imensa de dinheiro público é gasta pelos governos na compra de materiais didáticos impressos e digitais.

O emprego de MDDs pode modificar a dinâmica do ensino, as estratégias e o comprometimento de alunos e professores. Outrora, o professor encontrava escassos recursos tecnológicos à sua disposição, mas hoje existem inúmeras possibilidades de aplicação, acesso e facilidade de utilização desses recursos dentro e fora da sala de aula (Schlünzen Jr, 2009; Gonsales, 2014).

Em contextos de Curadoria Digital (CD), nas quais lida com a preservação e o gerenciamento do ciclo de vida de MDDs, esse problema torna-se ainda maior, pois a ação de selecionar e/ou avaliar esses materiais é uma tarefa primordial desse processo.

A concepção de avaliação de MDD, realizada por professores, vem sendo discutida por diversos autores (Campos, 1994; Gamez, 1998; Costa, 1999; Squires \& Preece, 1996 e 1999; Silva, 2002), que propõem instrumentos de avaliação segundo uma abordagem de classificação final. Assim como, por autores que apontam para uma abordagem da avaliação de MDD em contexto, ou seja, a partir da prática pedagógica do professor (Costa, 1999; Shaughnessy, 2002; Ramos, Teodoro, Maio, Carvalho, \& Ferreira, 2004; Silva, 2013, 2015; Silva \& Almeida, 2019).

Em um panorama abrangente, Cechinel (2017) realizou o estudo Modelos de Curadoria de Recursos Educacionais Digitais, pelo Centro de Inovação para a Educação Brasileira (Cieb), e aponta os modelos e critérios de curadoria utilizados para a formação de repositórios e avaliação da qualidade dos MDDs.

Com base nesse estudo, nossa proposta reside em compreender as concepções de pesquisadores sobre CD e suas percepções sobre como orientar os professores no processo de escolha de MDDs. Considerando que MDD pode ser adequado ou não a determinado contexto, segundo a intencionalidade pedagógica, nosso enfoque visa a contribuir com a CD, levando em conta a avaliação contextualizada dos materiais no formato digital (Silva, 2013).

\section{Fundamentação Teórica}

Tendo em vista os objetivos e o foco deste estudo, explicitamos o significado dos conceitos que o fundamentam: CD e avaliação de MDDs.

\subsection{Curadoria Digital}

A CD vem sendo discutida desde 2003, quando o conceito passou a ser debatido nas áreas de Ciência da Informação e Ciência da Computação, devido ao crescimento exponencial da informação digital. 
Diferentes áreas do conhecimento definem e trabalham com o conceito de $C D$ de maneiras variadas. Para o Digital Curation Center (DCC) (2019), a CD é um processo complexo, contínuo e interdisciplinar, que envolve a manutenção, preservação, avaliação, reavaliação, o uso e reúso, assim como a agregação de valores aos dados da pesquisa digital, por todo seu ciclo de vida.

O modelo de ciclo de vida da CD, proposto por Higgins (2008) (Fig. 1) e adotado pelo DCC, prevê ações genéricas de CD que podem ser aplicadas em diferentes contextos, inclusive com MDDs. O modelo sistematiza as ações de curadoria, as quais podem ou não ser aplicadas em sua totalidade; no entanto, necessita de uma equipe interdisciplinar que se envolva no processo (Nakano, 2019).

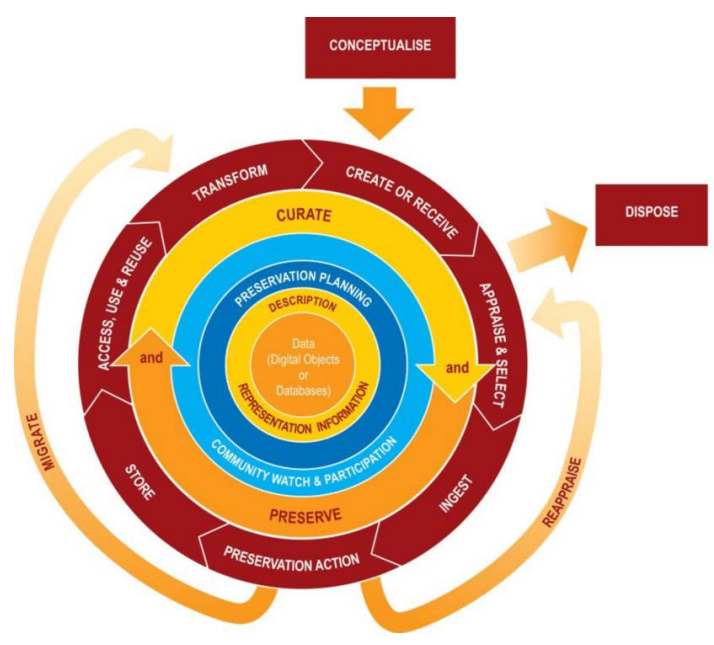

Fig. 1. Ciclo de vida da curadoria digital (Higgins, 2008) e traduzido por Nakano (2019).

As ações previstas na $C D$, de acordo com o modelo do $D C C$, podem incluir: conceituar; criar; acessar e usar; avaliar e selecionar; descartar; ingerir; preservar; reavaliar; armazenar; acessar e reutilizar; transformar.

Neste estudo, optamos por um recorte que enfatiza a necessidade da CD, especialmente voltada para a avaliação e seleção de MDDs.

\subsection{Avaliação de Materiais Didáticos Digitais}

De acordo com Silva (2013), o termo Material Didático Digital (MDD), proveniente das Tecnologias Digitais de Informação e Comunicação (TDIC), estabelece uma ligação entre a existência de software e de recursos educativos digitais; este último, podendo englobar também o conceito de Recurso Educativo Aberto (REA).

Corroborando com Ramos et al. (2011) e Chechinel (2017), os MDDs devem ser compreendidos aqui como quaisquer recursos digitais que possam ser utilizados no cenário educacional, abrangendo, assim, um contexto bastante amplo e que contempla diversas terminologias, comumente já estabelecidas com relação ao tema, como, por exemplo, objetos de aprendizagem, recursos educacionais abertos, objetos educacionais reutilizáveis, entre outras. Um recurso digital cujos elementos permitam a modelação, simulação, animação, combinação multimídia, induzindo a estratégias de ensino e modos de aprendizagem diversificados e que podem ser orientados para a manipulação dos objetos, para a observação ou reprodução dos fenômenos, ou, ainda, para a aprendizagem de conceitos e teorias, por meio da combinação de imagens, palavras e sons, etc. 
Podem ser de diferentes formatos; atender a distintos níveis de público e finalidades; ter distintos tamanhos ou granularidades; ser de diversos tipos; rodar em diferentes plataformas; possuir licenças e condições de uso diferenciadas; e abordar quaisquer temáticas ou disciplinas.

Nessa perspectiva, Ramos et al. (2011) alertam que é necessário e desejável distinguir os recursos que podem contribuir, de forma efetiva, para a inovação da prática pedagógica. Para Almeida e Valente (2011), os recursos que se sobressaem nessa direção são os softwares mais abertos, ou seja, "aqueles que permitem inserir novas informações, expressar o pensamento, estabelecer relações, desenvolver a interação social, compartilhar produções, trabalhar em colaboração [...]" (p. 9).

Com essa definição e distinção dos MDDs, é necessário determinar o uso que se faz deles em contexto pedagógico. Assim, o foco precisa estar na aplicação do MDD. Almeida (2005), Almeida e Valente (2011), trazem contribuições teóricas sobre a intencionalidade e importância da mediação e intervenção pedagógica do professor em contexto de uso de um MDD.

Independentemente do tipo de MDD, o professor precisa estar preparado para fazer a mediação e intervenção pedagógica, assim como para inserir o material nas atividades curriculares.

Evidencia-se, assim, que a utilização de um MDD, em contexto de uso, embora dependa de fatores tecnológicos, concretiza-se fundamentalmente na ação do professor.

Essa ação em contexto, associada com o domínio e a compreensão das potencialidades pedagógicas do MDD, é que, segundo Ramos et al. (2011), possibilitará e auxiliará os professores a adquirirem competências para a seleção criteriosa dos materiais, que poderá ser feita por meio da sua avaliação. Apesar da complexidade, essa análise, realizada pelo professor, permite compreender o que cada material pode oferecer e/ou possibilitar como potencial para o ensino e a aprendizagem.

Os autores Campos (1994), Squires e Preece (1996, 1999), Gamez (1998), Costa (1999) e Silva (2002), propõem instrumentos de avaliação já estudados por Silva (2009). No entanto, esses instrumentos avaliativos estão dentro de uma abordagem prognóstica.

Já Costa (1999), Shaughnessy (2002) e Ramos, Teodoro, Maio, Carvalho e Ferreira (2004), apontam para a abordagem da avaliação de MDD nessa perspectiva de referência ao contexto.

No caso deste estudo, a necessidade de considerar o contexto refere-se à escolha $\mathrm{e}$ avaliação de MDDs no decorrer da prática pedagógica do professor.

Para compreender o significado do termo contexto, Figueiredo e Afonso (2006) adotaram um modelo simplificado, que relaciona o aluno (p. ex., o professor em Formação Continuada) com o conteúdo e contexto, em um evento de aprendizagem (p. ex., escolha e avaliação de MDDs nas intervenções em contexto pedagógico da Formação Continuada) (Fig. 2). Esse modelo postula três definições: (1) Um evento de aprendizagem é uma situação em que um indivíduo aprende; (2) O conteúdo é a informação que foi estruturada e codificada como texto; os instrumentos avaliativos de MDDs; a palavra falada do formador, ou quaisquer outros meios utilizados nas ações presenciais e/ou a distância; (3) Contexto é o conjunto de circunstâncias relevantes para o aprendiz (nesse caso, o professor) construir seu conhecimento. 


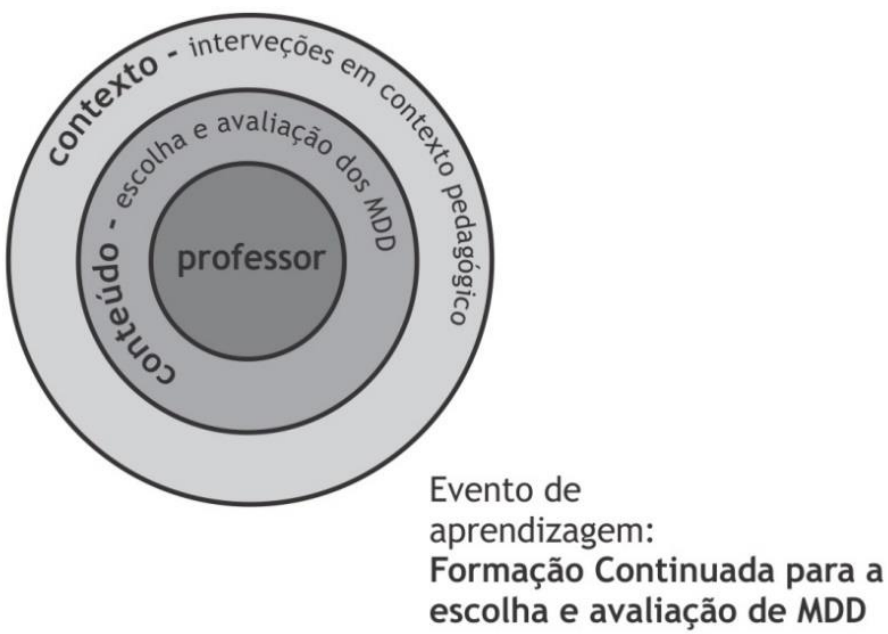

Fig. 2. Modelo simplificado de evento de aprendizagem em contexto, baseada em Figueiredo \& Afonso (2006).

A fronteira entre as camadas - conteúdo e contexto - torna-se difusa, ou seja, partindo-se da camada do conteúdo, remete-se à camada do contexto e vice-versa. Nessa perspectiva, "um gera o outro" e "um não pode existir sem o outro" e, assim, ambos demandam uma ação efetiva do professor, que tem clareza das intencionalidades pedagógicas implícitas no ato educativo.

\section{Percurso Metodológico}

No intuito de responder algumas indagações sobre: "Quais são as implicações do crescimento da oferta de Materiais Didáticos Digitais (MDDs) para os processos de ensino e aprendizagem?"; "Como e por quem esses materiais, no formato digital, estão sendo selecionados?", adotamos, neste estudo, uma abordagem qualitativa, pois, de acordo com Chizzotti (2006), assumem-se multiparadigmas de análise, adotam-se multimétodos de investigação para o estudo de um fenômeno em determinado contexto; além de procurarse tanto o sentido desse fenômeno quanto interpretar os significados dados pelos sujeitos.

Nessa perspectiva, adotamos como técnica de coleta de dados a entrevista, como processo reflexivo (Szymanski, 2004), por caracterizar-se como processo interativo e de busca da horizontalidade nas relações entre todos os participantes.

O instrumento da entrevista supõe um encontro interpessoal de todos os respondentes, "[...] num intercâmbio contínuo entre os significados e o sistema de crenças e valores, perpassados pelas emoções e sentimentos dos protagonistas" (Szymanski, 2004, p. 14). Também é um encontro interpessoal, que inclui a subjetividade dos protagonistas e a reflexão sobre a fala de ambos, assim, finalmente, juntos, vão construir um novo conhecimento, numa condição de horizontalidade (Szymanski, 2004).

Essa horizontalidade demanda alguns momentos da entrevista. Neste estudo, ocorreram três encontros, para que os pesquisadores mantivessem uma relação reflexiva. Nessa interação, abrimos um diálogo para que o tema em questão pudesse ser aprofundado.

$\mathrm{O}$ primeiro encontro com os pesquisadores resumiu-se à exposição dos objetivos da pesquisa e ao convite para que refletissem sobre o significado da escolha e avaliação de MDDs em um contexto de CD.

O segundo encontro foi agendado após a transcrição dos dados construídos na primeira entrevista, e colocados à disposição dos entrevistados, que puderam concordar, discordar ou acrescentar novos dados. 
No terceiro e último momento, os entrevistados puderam conhecer as interpretações das suas falas à luz das teorias requeridas, para que comentassem e trouxessem contribuições.

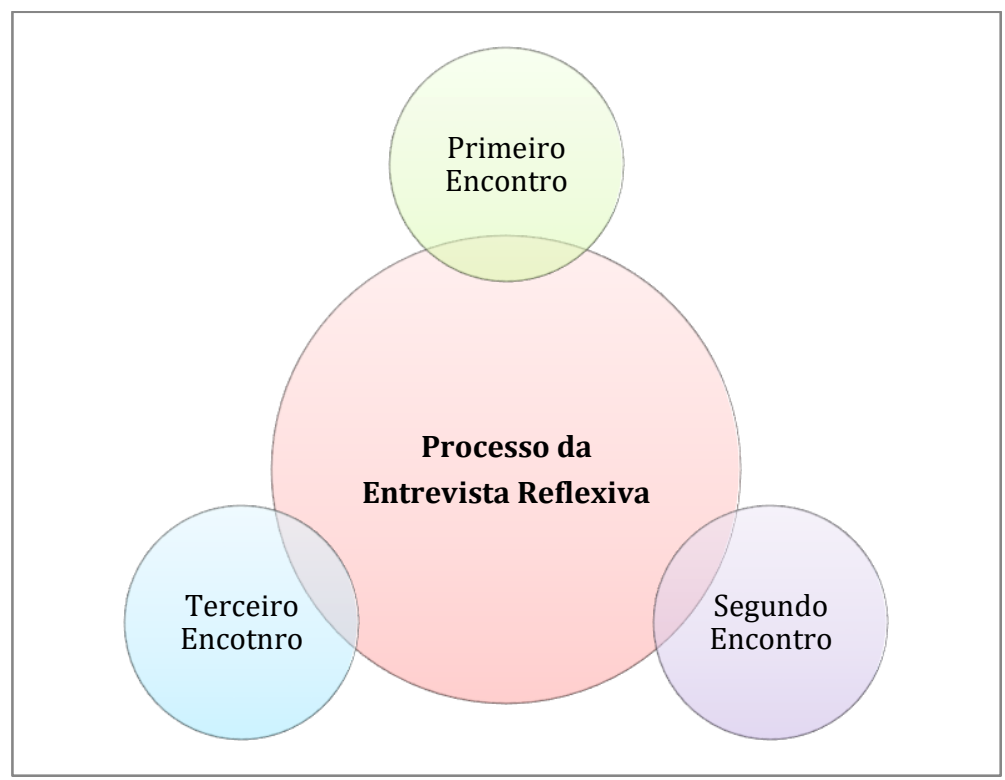

Fig. 3. Processo da entrevista reflexiva. Mostra uma figura que consiste nos três encontros com os participantes no processo da entrevista reflexiva.

A partir desses encontros, o objetivo foi compreender as concepções desses pesquisadores sobre $C D$ e suas percepções sobre como orientar os professores no processo de escolha de MDDs.

Vale pontuar que, o estudo foi realizado com pesquisadores e estudantes do doutorado em Educação stricto sensu, em uma universidade particular, no estado de São Paulo. Esses pesquisadores e estudantes, também são professores atuantes em Educação online e mediadores da formação de professores voltada à CD.

Para apoiar a análise dos dados, recorremos ao software webQDA (Costa, Moreira \& Souza, 2019), que permite o tratamento dos dados coletados, as codificações interpretativa e descritiva, e o questionamento dos dados (Neri de Souza, Neri de Souza, \& Costa, 2016). Assim, utilizamos a ferramenta Fontes, a primeira ação do pesquisador com o webQDA. Essa área pode ser organizada de acordo com a necessidade de quem utiliza o software; os tipos de documentos; ou a função de cada um (Neri de Souza, Neri de Souza, \& Costa, 2016). Neste estudo, as fontes utilizadas e organizadas para a constituição dos materiais de análise foram as entrevistas com os pesquisadores.

Antes de iniciar o trabalho com a Codificação, foi necessária uma leitura atenta dos extratos dos dados, com vistas a criar a/s temática/s, dimensões, os indicadores, ou as categorias, tanto as descritivas como as interpretativas (Neri de Souza, Neri de Souza, \& Costa, 2016). Para este estudo, optou-se, inicialmente, por criar duas temáticas: Concepções dos pesquisadores sobre CD; percepções dos pesquisadores sobre como orientar professores no processo de CD. 


\section{Apresentação e Discussão dos Resultados}

Conforme explicamos anteriormente, o estudo foi realizado com pesquisadores e estudantes do doutorado em Educação stricto sensu, esses participantes também têm experiência em cursos de formação continuada de professores com foco em CD.

As discussões dos resultados trazem um diálogo entre os fundamentos teóricos abraçados por Silva (2013); os conceitos de CD (Cechinel, 2017); assim como os dados construídos por meio das entrevistas reflexivas com os pesquisadores.

A análise das especificidades das entrevistas reflexivas tornou evidente a relação entre os temas emergentes, pelo fato de ter enfatizado as concepções e percepções das temáticas pelos pesquisadores.

A Tabela 1, apresenta os temas e subtemas emergentes, a partir da análise de conteúdo das entrevistas reflexivas, além das referências, as quais foram elaboradas a partir da utilização do software webQDA, mais especificamente na ferramenta Codificação.

Tabela 1. Temas, subtemas e número de referências.

\begin{tabular}{|c|c|c|}
\hline Temas emergentes & Subtemas & Referências \\
\hline \multirow{5}{*}{$\begin{array}{l}\text { [1] Concepções dos } \\
\text { pesquisadores sobre o processo } \\
\text { de curadoria digital }\end{array}$} & & 30 \\
\hline & $\begin{array}{l}\text { Apropriação sobre o } \\
\text { conceito de curadoria }\end{array}$ & 6 \\
\hline & $\begin{array}{l}\text { Ressignificação do } \\
\text { conceito de curadoria }\end{array}$ & 9 \\
\hline & $\begin{array}{l}\text { Apropriação } \\
\text { tecnológica do } \\
\text { curador para a } \\
\text { construção da } \\
\text { curadoria de MDDs }\end{array}$ & 5 \\
\hline & $\begin{array}{l}\text { Critérios para a } \\
\text { construção da } \\
\text { curadoria digital de } \\
\text { MDDs }\end{array}$ & 10 \\
\hline \multirow{4}{*}{$\begin{array}{l}\text { [2] Percepções dos pesquisadores } \\
\text { sobre como orientar os } \\
\text { professores no processo de } \\
\text { curadoria digital }\end{array}$} & & 16 \\
\hline & $\begin{array}{l}\text { Contexto para } \\
\text { elaboração da } \\
\text { curadoria digital }\end{array}$ & 6 \\
\hline & $\begin{array}{c}\text { Apropriação } \\
\text { tecnológica do } \\
\text { curador para a } \\
\text { construção da } \\
\text { curadoria de MDDs }\end{array}$ & 5 \\
\hline & $\begin{array}{l}\text { Volume de } \\
\text { tecnologias e } \\
\text { informações }\end{array}$ & 5 \\
\hline Total de Referências & & 46 \\
\hline
\end{tabular}


O primeiro tema emergente, trata sobre as concepções dos pesquisadores sobre o processo de curadoria digital, a partir da contextualização da temática, evidenciou-se a necessidade cada vez mais premente, na atualidade, de refletir sobre $C D$, processo que pode preparar o professor para uma análise crítica e reflexiva a respeito dos MDDs, voltada para um processo de escolha e avaliação desses materiais no contexto de sua utilização, considerando as características contextuais, as intenções dos professores e a concretização desse processo em sua prática pedagógica (Silva, 2013).

Considerada essa perspectiva reflexiva, iniciamos as problematizações com os pesquisadores, especificamente, as concepções sobre o processo de CD.

As entrevistas com esses pesquisadores possibilitaram constatar um movimento de construção de significados, que foram sendo ressignificados no decorrer do processo.

Esses significados estão articulados nas falas dos pesquisadores e, por isso, optamos por mantê-las na íntegra para facilitar a compreensão da pesquisa, apenas suprimindo as partes fora do contexto.

[...] eu confesso que eu não tinha grandes concepções sobre curadoria digital. Aliás, eu fui descobrir o que era curadoria digital [...] justamente fazendo o trabalho. [...] Depois de ter passado por essa experiência de formação de curadores, eu posso te dizer que ela é algo que passou a existir, é algo que não existia pra mim, não fazia parte da minha realidade, não fazia parte das coisas que eu observava [...]. [Pesquisador 1].

Eu não conhecia o conceito sobre curadoria digital. Na verdade, eu vivenciei o conceito. [Pesquisador 2].

A palavra curadoria vem da Arte, ela faz esse papel de organizar, de filtrar o conteúdo. Quando a gente fala de curadoria digital, eu acho que tem duas questões. A curadoria digital, eu acho que ela pode ser feita por pessoas, mas ela também pode ser feita por algoritmos. E quando a gente fala de curadoria da informação, que aí sim eu acho que tem essa questão de selecionar, olhar, pegar uma produção já feita e ressignificar essa produção de alguma maneira, usando filtros, usando organizadores, hierarquização... eu acho que é um pouco esse o conceito que eu tenho de curadoria. [Pesquisador 3].

Os dois primeiros extratos revelam que os pesquisadores foram construindo suas concepções sobre CD na prática. Embora a experiência de formação a que se referem tenha como foco de estudos a $C D$, eles não atuavam com esse enfoque e tomaram contato com essa proposta ao participar da preparação para exercer a tutoria nessa formação.

Entretanto, o terceiro extrato apresenta uma concepção elaborada sobre o conceito de $\mathrm{CD}$, oferecendo duas abordagens, além de resgatar a origem da curadoria organizada por pessoas, assim como explicitar a abordagem da curadoria de informações ou de conteúdo. Vale considerar que esta pesquisadora tem outras vivências com curadoria.

Castilho (2015) explica que, a partir do século XXI, a abordagem da curadoria de informações ou conteúdos digitais começou a ser amplamente utilizada, em consequência do aumento constante e exponencial no volume de dados e informações publicados. Dessa forma, o conceito de CD está relacionado ao avanço das TDIC e, em consequência, ao aumento considerável da disponibilidade, multiplicidade, diversidade e à própria noção de conteúdo educativo desenvolvido para diversas áreas do conhecimento.

Após constatada a complexidade que envolve as concepções sobre $C D$, esses pesquisadores revelaram que começaram um processo de ressignificação, em decorrência do processo de curadoria de MDDs.

Critérios muito fechados não precisa, precisamos de referências, mas não muito fechadas. [...] eles vão surgindo, porque é espontâneo, aí a gente vai ampliando, dentro do que a gente vai colhendo, penso assim... [Pesquisador 2]. 
[...] a origem desse objeto, se não é uma fake news, [...] seleção de conteúdo, de possibilidade de reproduzir, então se tinha direitos autorais ou não tinha, se era aberto. Ah! Qualidade de imagem, qualidade não somente de conteúdo, mas a qualidade de imagem... problemas técnicos também, quando é digital, se tudo funciona, se o link que está lá não sumiu, porque as coisas digitais são muito rápidas... [...] Acho que teriam sempre que ter, para curar algum objeto digital. [...] verificar as habilidades da BNCC. [...] Acessibilidade é super importante, o funcionamento [...]. Tanto de conteúdo, quanto de parte técnica. Eu acho que precisa ter, pois esses dois critérios são muito importantes na curadoria. [Professor/ pesquisador 3].

Esses extratos retratam que, a partir das reflexões sobre a elaboração de CD, os professores/pesquisadores corroboram a necessidade da apropriação tecnológica do curador para a construção da curadoria de MDDs. Os estudos sobre apropriação das TDIC indicam que esse processo não é simples, requer tempo e acontece em fases (Almeida \& Valente, 2011)

Os extratos também levantam alguns critérios, com abordagens pedagógica e técnica, como, por exemplo, a ética; a necessidade de verificar a veracidade; a qualidade dos conteúdos; e as relações estabelecidas com as habilidades da BNCC, além da qualidade técnica das imagens e a acessibilidade da informação.

Além desses critérios, emergiu a importância do contexto de atuação no qual estamos inseridos, ou seja, a curadoria de MDDs contextual, na medida em que não é possível compreender apenas o design pedagógico ou técnico, desconsiderando o contexto em que este se insere (Silva, 2013).

O segundo tema emergente, refere-se às percepções dos pesquisadores sobre como orientar os professores no processo de CD, os quais estão explicitadas, a seguir, em trechos das entrevistas.

O primeiro extrato, retoma a importância da apropriação tecnológica, pois sem ela, o processo de CD fica difícil e demanda muito mais tempo, além de inúmeros conflitos, como explicam Almeida e Valente (2011): "[...] de ordem profissional e com suas crenças pessoais, sobre a educação e sobre como proceder em sala de aula" (p. 46). Além disso, o pesquisador 3 reforça a importância da formação de curadores.

[...] essa apropriação tecnológica, apesar de a gente estar em 2020, não é igual para todo mundo... [...] eu entendo que, sem curadoria, não tem qualidade. Então, nós podemos ter diversas ferramentas dentro do ambiente tecnológico... pode ter um Objeto Digital de Aprendizagem (ODA), pode ter um plano de aula e outras coisas... mas, se elas não tiverem esse cuidado, esse tratamento, essa curadoria, realmente bem feita, bem estruturada, é só mais uma coisa poluindo... sem efetivamente agregar qualidade, conhecimento ou desenvolvimento de quem está buscando esse objeto, por exemplo. Então, eu entendo que a minha concepção mudou. A importância que eu dou a um curador, bem formado, bem preparado para enxergar o que ele pode melhorar... eu entendo como bastante significativo. E, tenho cá minhas dúvidas, se realmente tem tantas pessoas preparadas para fazerem essa curadoria, de maneira qualitativa, de modo que os objetos, os planos ou qualquer outra coisa que esteja sendo curada, realmente possa receber uma certificação de qualidade. [Pesquisador 1]. 
Fundamental, hoje! Eu até escrevi numa parte da minha dissertação sobre aprendizagem, eu uso o Pozo [...] E ele fala de uma obesidade digital, uma obesidade de informações, é um fast-food de informações, que hoje a coisa mais importante é a curadoria digital, que é essa seleção mesmo, de tudo o que a gente tem, dessa informação... Então ele fala que aprendizagem não acontece mais... que hoje o centro não é mais o professor, o aluno aprende em todos os lugares o tempo todo... E depois vem um conceito da aprendizagem ubíqua, que a Santaella fala... que realmente é isso, mas se não é uma coisa feita com orientação, ou com seleção, ou com curadoria... a gente aprende muito pouco, a gente acaba se perdendo nessa quantidade de informação, de conteúdo digital que a gente tem. Então, eu acredito muito que hoje seja o papel do professor, um dos papéis do professor, seja essa curadoria de todos esses objetos digitais, de tudo isso que a gente tem na educação, para selecionar e ajudar... e informar mesmo pensadores críticos, que possam usar essa rede, essa quantidade de informação de uma maneira crítica, [...] e como vai usar isso, que caminho vai usar, o que é seguro e o que não é seguro, o que é informação, se vem de uma fonte segura ou não... Então eu acho que isso na educação é fundamental. É o caminho! [Pesquisador 3].

De modo geral, esse extrato revela sua percepção sobre o processo de curadoria, que possibilitou reflexões relacionadas à quantidade de MDDs disponíveis.

Pozo (2008) explica que um enorme volume de informações é disponibilizado a cada dia, e que "[...] estamos sendo abarrotados, superalimentados de informação, na maioria das vezes em formato fast food" (p. 35). E, por isso, faz-se necessário e importante refletir sobre os desafios que nos são impostos, como profissionais e professores, situados nesse contexto de "abundância" de tecnologias e informações (Silva, 2013); de escolher e/ou avaliar os MDDs. Caso contrário, há uma tendência de levarmos tudo isso a projeções negativas, ou seja, tememos e rejeitamos o que deixamos de entender e dar sentido.

\section{Considerações Finais}

O impacto das tecnologias digitais mostra-se significativo, na medida em que estão presentes no ensino. Considerada a relevância do processo de escolha de MDDs no contexto de CD, buscou-se, neste artigo, compreender as concepções de pesquisadores sobre CD e suas percepções sobre como orientar os professores no processo de escolha de MDDs. Para isso, nos valemos dos estudos realizados por Silva $(2009,2013,2015)$ sobre avaliação de MDDs; estudos sobre CD (Castilho, 2015; Cechinel, 2017; Nakano, 2019). Finalmente, os dados coletados em entrevistas reflexivas, realizadas no primeiro semestre de 2020, com três pesquisadores que forneceram referências para levantarmos novas possibilidades de diálogo entre a avaliação de MDDs e CD, o que sugere uma nova abordagem de formação de professores, a partir do contexto no qual estão inseridos.

Os extratos sobre as concepções e percepção, em relação ao processo de $C D$ por professores, tiveram o significado, para os pesquisadores, de que era uma temática fora de seu domínio, mas, a partir da aproximação e apropriação dessa temática, conseguiram compreender a sua relevância. Na atualidade, a realização de CD no processo de ensino, por professores, é uma exigência e uma nova atribuição. Nesse sentido, os profissionais precisam ser preparados para assumir tal responsabilidade. Por isso, a CD mostra-se mais uma vez relevante e, desta vez, no enfoque em formadores que atuam nas universidades com novos professores.

Além desses aspectos, faz-se necessário ressaltar os professores são os atores e protagonistas desse processo. Nessa perspectiva, quem decide sobre a CD, continua sendo ele, a partir também das problematizações sobre como, por que, o que, para que e a serviço do que, deve-se utilizar determinado MDD.

É pertinente considerar também, que os desafios a serem enfrentados na adoção de práticas de avaliação de MDDs no contexto de CD, são inúmeros, porém mostra-se em sinergia com as demandas atuais da formação de professores. 
Entretanto, esse processo poderá provocar questionamentos e gerar insegurança nos professores, pois trazem novas perspectivas, demanda tempo e requerer reflexão sobre as práticas pedagógicas.

Por fim, ressalta-se que há limitações, no presente estudo, pois foi realizado com três pesquisadores, doutorandos em Educação, professores atuantes em Educação on-line e mediadores da formação de professores voltada à CD. Porém, é importante salientar que teve como base estudo anterior realizado por Silva (2013), em projeto de formação continuada. Por tudo isso, ainda acreditamos ser necessário ampliar os estudos, com outros participantes, no sentido de ouvir, por exemplo, professores participantes de cursos voltados à CD e docentes de cursos de licenciatura, para suscitar novas problematizações.

\section{Referências}

Almeida, M. E. B. (2005). Educação, projetos, tecnologia e conhecimento. 2a ed. São Paulo: Proem.

Almeida, M. E. B., \& Valente, J. A. (2011). Tecnologias e currículo: trajetórias convergentes ou divergentes? São Paulo: Paulus.

Almeida, M. E. B., \& Silva, K. A. G. (2014). Formação de professores a distância e as perspectivas de articulação entre teoria e prática por meio de ambientes on-line. Educar em Revista, n. SPE4, p. 129-148.

Campos, G. H. B. (1994). Metodologia para avaliação da qualidade de software educacional: diretrizes para desenvolvedores e usuários. Tese (Doutorado em Engenharia da Produção) Universidade Federal do Rio de Janeiro, Rio de Janeiro, Rio de Janeiro.

Castilho, C. A. V. (2015). O papel da curadoria na promoção do fluxo de notícias em espaços informativos voltados para a produção e conhecimento. Tese (Doutorado em Engenharia e Gestão do Conhecimento) - Universidade Federal de Santa Catarina, Florianópolis, 2015.

Cechinel, C. (2017). Modelos de curadoria de recursos educacionais digitais. Estudos 5: Centro de Inovação para a Educação Brasileira (Cieb). Disponível em http://cieb.net.br/cieb-estudos-5modelos-de-curadoria-de-recursos-educacionais-digitais/. Acesso em: 04 jan. 2021.

Chizzotti, A. (2006). Pesquisa qualitativa em ciências humanas e sociais. Petrópolis: Vozes.

Costa, F. A. (1999). Contributos para um modelo de avaliação de produtos multimédia centrado na participação dos professores. Simpósio Ibérico de Informática Educativa, 1999, Aveiro. Anais eletrônicos do I Simpósio Ibérico de Informática Educativa. Aveiro/Portugal: Universidade de Aveiro.

Costa, A. P., Moreira, A., \& Neri de Souza, F. (2019). webQDA - Qualitative Data Analysis. Aveiro Portugal: Aveiro University and MicrolO. Retrieved from www.webqda.net (Original work published).

Figueiredo, A. D., \& Afonso, A. P. (2006). Context and Learning: A Philosophical Framework. In Figueiredo, A. D.; Afonso, A. P. (Eds.). Managing learning in virtual settings: the role of context. Hershey, PA, USA: Information Science Publishing.

Gonsales, P. (2014). Recursos educacionais abertos, formação de professores e o desafio de educar na cultura digital. Comitê Gestor da Internet no Brasil. Pesquisa sobre o uso das tecnologias de informação e comunicação nas escolas brasileiras: TIC Educação 2013 [livro eletrônico] [coordenação executiva e editorial, Alexandre F. Barbosa / tradução DB Comunicação]. São Paulo: Comitê Gestor da Internet no Brasil.

Higgins, S. (2008). The DCC Curation Lifecycle Model. The International Journal of Digital Curation, Edinburgh, v. 3, n. 1.

Nakano, N. (2019). Princípios do design da informação na curadoria digital de ambientes virtuais de aprendizagem sob a perspectiva da ciência da informação. Tese (Doutorado em Ciência da Informação) - Universidade Estadual Paulista (Unesp), Marília.

Neri de Souza, F., Neri de Souza, D. \& Costa, A. P. (2016). Asking questions in the qualitative research context. The Qualitative Report, 21(13), pp. 6-18.

Pozo, J. I. (2008). Aprendizes e mestres: a nova cultura da aprendizagem. Porto Alegre: Artmed. 
Ramos, J. L., Teodoro, V. D., Maio, V. M., Carvalho, J. M. \& Ferreira, F. M. (2004). Sistema de avaliação, certificação e apoio à utilização de software para a educação e formação. Cadernos Sacausef (v. 1, pp. 21-44), Portugal.

Ramos, J. L., Teodoro, V. D., Maio, V. M., Carvalho, J. M., \& Ferreira, F. M. (2011). Recursos educativos digitais: reflexões sobre a prática. Cadernos Sacausef (v. 7, pp. 11-35), Portugal.

Shaughnessy, M. R. (2002). Educational software evaluation: a contextual approach. Ohio. Thesis (Doctorate of Philosophy) - Department of Germanic Languages and Literatures, McMicken College of Arts and Sciences, University of Cincinnati, Ohio.

Squires, D., \& Preece, J. (1996). Usability and learning: evaluating the potential of educational software. Computer and Education, 27(1), pp. 15-22.

Squires, D., \& Preece, J. (1999). Predicting quality in educational software: evaluating for learning, usability and synergy between them. Interacting with Computers, 11(5), pp. 467-483.

Schulüzen Jr, K. As tecnologias de informação e comunicação na formação inicial do professor: um desafio a ser superado. In: Pinho, S. Z. (Org.). (2009). Formação de educadores: o papel do educador e sua formação. São Paulo: Unesp, 2009.

Silva, C. R. O. (2002). Maep: Um método ergopedagógico interativo de avaliação para produtos educacionais informatizados. Tese (Doutorado em Engenharia de Produção) - Universidade Federal de Santa Catarina, Florianópolis.

Silva, K. A. G. (2009). Validação participativa de instrumentos avaliativos de software educativo por professores do ensino fundamental e médio. Dissertação (Mestrado em Design) - Programa de pós-graduação em Design, Universidade Federal do Paraná (UFPR), Paraná.

Silva, K. A. G. (2013). Avaliação de material didático digital na formação continuada de professores do ensino fundamental: uma pesquisa baseada em design. Tese (Doutorado em Educação e Currículo) - Programa de pós-graduação em Educação e Currículo, Pontifícia Universidade Católica de São Paulo (PUC-SP), São Paulo.

Silva, K. A. G. (2015). Formação De Professores Para A Escolha De Materiais Didáticos Digitais: Mediações Contextualizadas. Revista Educativa-Revista de Educação, 18(1), 81-101.

Szymanski, H. (Org.). (2004). A entrevista na educação: a prática reflexiva. Brasília/DF: Liber Livro Editora. 